\title{
Phaseolus vulgaris L. Extract: Alpha-Amylase Inhibition against Metabolic Syndrome in Mice
}

\author{
Laura Micheli ${ }^{1}$, Elena Lucarini ${ }^{1}$ (D), Elena Trallori ${ }^{1}$, Carmen Avagliano ${ }^{2}$, Carmen De Caro ${ }^{3}$, \\ Roberto Russo ${ }^{2}$, Antonio Calignano ${ }^{2}$, Carla Ghelardini ${ }^{1}$, Alessandra Pacini ${ }^{4, \dagger}$ and \\ Lorenzo Di Cesare Mannelli $1, *,+$ (i) \\ 1 Department of Neuroscience, Psychology, Drug Research and Child Health-Neurofarba-Pharmacology and \\ Toxicology Section, University of Florence, 50139 Florence, Italy \\ 2 Department of Pharmacy, University of Naples “Federico II" Naples, 80131 Naples, Italy \\ 3 Department of Science of Health, School of Medicine and Surgery, University of Catanzaro, 88100 Catanzaro, \\ Italy \\ 4 Department of Experimental and Clinical Medicine, Anatomy and Histology Section, University of Florence, \\ 50134 Florence, Italy \\ * Correspondence: lorenzo.mannelli@unifi.it; Tel.: +39-055-275-8395 \\ + These authors contribute equally to this work.
}

Received: 21 June 2019; Accepted: 29 July 2019; Published: 1 August 2019

\begin{abstract}
To examine the effects of the alpha-amylase inhibitor isoform 1 called phaseolamin, a standardized extract from white kidney beans (Phaseolus vulgaris L.) was tested against the hallmarks of metabolic syndrome. The efficacy of a per os repeated treatment with P. vulgaris extract $(500 \mathrm{mg} / \mathrm{kg})$ was compared with metformin $(100 \mathrm{mg} / \mathrm{kg})$ and atorvastatin $(10 \mathrm{mg} / \mathrm{kg})$ in a model of metabolic syndrome evoked by prolonged high fat diet (HFD; week 1 to week 19) in C57BL/6 mice. Bean extract and compounds administration started after metabolic syndrome establishment (week 11). P. vulgaris extract reduced the body weight overtime, as well as effectively lowered glycaemia, triglycerides, and cholesterol. On week 19, bean extract normalized the HFD-evoked tolerance to glucose and insulin. According to the phytochemical characterization, it inhibited the alpha-amylase activity. Animals treated with the extract were rescued from motor impairments and nociceptive threshold alterations induced by HFD. Specific organs analysis revealed that $P$. vulgaris extract decreased hepatic steatosis and lipid peroxidation in liver. It protected the heart from HFD oxidative alterations increasing the expression of the detoxifying enzymes catalase and glutathione reductase, and normalizing NADH dehydrogenase level. The histological analysis of aorta showed a protection about the development of fatty streaks in the muscular layers. In conclusion, a prolonged treatment with the standardized extract of $P$. vulgaris significantly reduced several pathological features related to a metabolic syndrome-like condition; a multifactorial approach that candidates this vegetal product as a possible therapeutic option against metabolic syndrome.
\end{abstract}

Keywords: P. vulgaris extract; metabolic syndrome; HFD, alpha-amylase inhibitor

\section{Introduction}

Metabolic syndrome was first described by [1], who named it "Syndrome X". Since then, the interest from the investigators has increased constantly, and many were the names given to it, e.g., the insulin-resistance syndrome, the hypertriglyceridemic waist, and metabolic syndrome. The latter, the most used term in the cardiovascular field, will be used in this article to refer to this syndrome [2].

The syndrome is a group of co-occurring and interconnected biochemical and metabolic disorders, among which the hallmarks are altered glucose metabolism, insulin resistance, dyslipidemia, 
hypertension, abdominal obesity, hepatic steatosis, and hypercholesterolemia. The modern lifestyle, defined by over-nutrition and very little physical exercise, has recently increased its incidence. The array of disorders which compose metabolic syndrome often represent the preparatory soil for type 2 diabetes and atherogenic cardiovascular diseases [2-4].

Treatment strategies for metabolic syndrome could involve the use of nutraceuticals, most of which have plant origins (phytochemicals) associated with lifestyle improvement $[5,6]$.

The pancreatic alpha-amylase inhibitor isoform 1 (alpha-AI 1), also known as phaseolamin, is a constituent protein of the common white and kidney beans (Phaseolus vulgaris L.). Next to it, there are two other isoforms and an alpha-amylase inhibitor like (alpha-AI 2, alpha-AI 3 and alpha-AIL, respectively). The most widely distributed in the plant is the alpha-AI 1, which represents about one tenth of the total seed protein content [7]. This enzyme hampers the activity of some mammalian and insect alpha-amylase, but it does not affect the plant endogenous enzyme. Interestingly, each variety of $P$. vulgaris produces an alpha-AI type 1 with a fairly different primary structure; nevertheless, all the enzymes show the same inhibitory activity on animal amylases [8]. This enzyme was discovered in 1945 by [9], and was characterized and named "phaseolamin" in 1975 by [10]. Since then, phaseolamin was tested for its efficacy as a starch blocker and purified extracts were used as human dietary supplements with anti-hyperglycaemic and anti-obesity purpose [11]. The results were not as expected, probably because of an insufficient inhibitory activity on human alpha-amylase. The successive progresses made in the protein extraction, purification, and standardization fields have allowed the production of bean plant extracts with higher and more effective inhibitory activity on carbohydrate metabolism [7].

Moreover, although $P$. vulgaris is not the only plant to contain alpha-amylase inhibitors, as some cereal plants also produce them, there is no report about severe side effects correlated to its alpha-AIs, while the cereal-derived isoforms are associated with dermatitis and asthma [7].

The aim of the present study was to evaluate the efficacy of a chronic treatment with a standardized seed extract from $P$. vulgaris, containing $6 \%$ of the non-nutritive bioactive compound phaseolamin on a murine model of metabolic syndrome to compare its efficacy to a chronic treatment with two reference drugs for hyperglycaemia and hypercholesterolemia-i.e., metformin and atorvastatin, respectively. The metabolic disorders were induced by feeding with a high fat diet (HFD), containing $60 \%$ fats out of total calories, and the results were compared with those obtained from mice fed with normal diet. HFD-fed animals, indeed, reached the pathological state after 11 weeks of enriched alimentation, as confirmed by remarkably altered blood levels of glucose, triglycerides, and cholesterol. Further ex vivo analysis completed the investigation on the grade of regression of the disease reached, following each treatment.

\section{Materials and Methods}

\subsection{Animals}

Male C57BL/6 mice (Envigo, Varese, Italy) weighing approximately $20 \mathrm{~g}$ at the beginning of the experimental procedure were used. Animals were used in Ce.S.A.L (Centro Stabulazione Animali da Laboratorio, University of Florence) and used at least one week after their arrival. Twelve mice were housed per cage (size $26 \times 41 \mathrm{~cm}$ ), kept at $23.0 \pm 1.0^{\circ} \mathrm{C}$ with a $12 \mathrm{~h}$ light/dark cycle, with lights on at 7 a.m.; during acclimatization they were fed a standard laboratory diet and tap water ad libitum.

All animal manipulations were carried out according to the Directive 2010/63/EU of the European parliament and of the European Union council (22 September 2010) on the protection of animals used for scientific purposes. The ethical policy of the University of Florence complies with the Guide for the Care and Use of Laboratory Animals of the US National Institutes of Health (NIH Publication no. 85-23, revised 1996; University of Florence assurance number: A5278-01). Formal approval to conduct the experiments described was obtained from the Animal Subjects Review Board of the University of Florence. Experiments involving animals have been reported according to ARRIVE guidelines [12]. All efforts were made to minimize animal suffering and to reduce the number of animals used. 


\subsection{Induction of Metabolic Syndrome}

Metabolic syndrome was induced by feeding the animals with a high fat diet (HFD; Research Diets, New Brunswick, NJ) for 19 weeks ad libitum. The model is consistent, with minor modification, to what was previously published [13-15]. The HFD contained $60 \%$ fat, $20 \%$ protein, and $20 \%$ carbohydrate, as a percentage of total Kcal [16]. Control animals were fed ad libitum for 19 weeks with a standard diet ( $24 \%$ protein, $58 \%$ carbohydrate, $18 \%$ fat; Envigo, Varese, Italy).

\subsection{Extract Preparation}

The vegetal extract used in the present study (Beanblock ${ }^{\circledR}$; Indena S.p.A., Milan, Italy) is a standardized dry extract containing an alpha-amylase inhibitor and phytohaemagglutinin. Briefly, $P$. vulgaris dry extract was prepared by means of aqueous extraction and alcoholic precipitation from the common kidney bean (P. vulgaris). Bean extract was obtained by extraction with citrate buffer and precipitation with ethanol. The extract is characterized by a standardized composition of $8.5 \%$ $(w / w)$ tested $\alpha$-amylase inhibitor, with inhibiting activity $=1400 \mathrm{U} / \mathrm{mg}$, and phytohaemagglutinin (haemagglutinating activity 16 haemagglutinating units $/ \mathrm{mg}$ ). The manufacturing process is described in detail by $[17,18]$.

\subsection{Treatments}

P. vulgaris dry extract $500 \mathrm{mg} \mathrm{kg}^{-1}$ (Indena S.p.A.), metformin $100 \mathrm{mg} \mathrm{kg}^{-1}$ (Carbosynth, UK), and atorvastatin $10 \mathrm{mg} \mathrm{kg}^{-1}$ (Carbosynth, UK) were suspended in $1 \%$ carboxymethylcellulose sodium salt (CMC; Sigma-Aldrich) and daily per os administered $30 \mathrm{~min}$ before the dark phase of the circadian light/dark cycle in the animal facility from week 11 until week 19 . The doses of P. vulgaris, metformin, and atorvastatin were chosen on the basis of the literature [18-20].

\subsection{Body Weight and Food Intake}

During the experiment, the body weight of mice was measured every 3 days, while the food intake was measured weekly.

\subsection{Collection of Blood and Analytical Methods}

Blood was collected from the facial vein of fed mice under light ether anaesthesia into eppendorf tubes containing heparin $(20 \mu \mathrm{L}, 25,000 \mathrm{IU} / 5 \mathrm{~mL})$ twice a month, starting from week. Samples were analyzed for glucose, triglycerides, and total cholesterol levels using a Reflotron reflectance photometric analyser (Reflotron, Roche Diagnostics and Vitros, Johnson \& Johnson). Low-density lipoprotein (LDL), high-density lipoprotein (HDL) cholesterol, and alpha-amylase activity were measured using the same method only in week 19. Plasmatic levels of ghrelin and insulin were measured in week 19 using ELISA kit (Wide range mouse insulin immunoassay kit, Biorbyt; Mouse ghrelin enzyme immunoassay kit, Biorbyt). Alpha-amylase activity was measured.

\subsection{Glucose and Insulin Tolerance Tests}

On week 19, the glucose tolerance test (GTT) and the insulin tolerance test (ITT) were performed by intraperitoneal injections of glucose $\left(1 \mathrm{mg} \mathrm{kg}^{-1}\right)$ and insulin $\left(1 \mathrm{U} \mathrm{kg}^{-1}\right.$; Humalog, Lilly) on fed animals, respectively. Blood glucose was measured by Accu-Check Aviva at $0 \mathrm{~min}, 15 \mathrm{~min}$, and $30 \mathrm{~min}$ after glucose injections for GTT, and at $0 \mathrm{~min}, 30 \mathrm{~min}$, and $60 \mathrm{~min}$ after insulin injection for ITT.

\subsection{Behavioral Tests}

On week 19, the motor coordination was measured by the Rota rod test according to [21]. Mechanical allodynia was measured by Von Frey test as described by [22]. TheHargreaves' Plantar test was used to measure the thermal nociceptive threshold as described by [23]. To evaluate anxiety-related 
behavior, the Elevated plus maze test was conducted as previously described by [24,25]. More details in the Supplementary Materials.

\subsection{Tissues Explant}

On week 19, after the behavioral measurements and the biochemical analysis, mice were sacrificed by cervical dislocation and tissues explant was performed. In particular, brain, liver, heart, aorta, epidydimal white adipose tissue, and kidney were collected.

\subsection{Liver and Kidney Histopathology}

Samples were fixed in $4 \%$ formalin and processed for embedding and sectioning. More details in the Supplementary Materials.

\subsection{Analysis of Lipid Deposition in the Arterial Wall}

The aortas were washed with phosphate-buffered saline (PBS) and then fixed with $4 \%$ paraformaldehyde overnight. The proximal aorta attached to the heart was used to prepare cryo-sections. Cryo-sections $(8 \mu \mathrm{m})$ were cut, collected, and stained with oil red $\mathrm{O}$ according to [26] with minor modification. The quantification of stained lipids was determined by calculating the positive area in comparison to the total cross-sectional vessel wall area by using Image-Pro Plus software 4.5 (Media Cybernetics). The percentage was calculated from five sections for each animal.

\subsection{Lipid Peroxidation (Thiobarbituric Acid-Reactive Substances Assay)}

Thiobarbituric acid-reactive substances (TBARS) assay was assessed as an index of lipid peroxidation according to [27]. More details in the Supplementary Materials.

\subsection{Carbonylated Proteins}

Carbonylated proteins were evaluated in plasma and heart tissue homogenate. Plasma or heart tissue protein extracts were quantified by BCA. Twenty micrograms of each sample were denatured by $6 \%$ SDS and derivatized by 15-min incubation with 2-4 dinitrophenyl hydrazine (DNPH; Sigma-Aldrich, Italy) at room temperature. More details in the Supplementary Materials.

\subsection{Western Blot Analysis}

Hearts were homogenized in lysis buffer containing $50 \mathrm{mM}$ Tris- $\mathrm{HCl} \mathrm{pH}$ 8.0, $150 \mathrm{mM} \mathrm{NaCl}, 1 \mathrm{mM}$ EDTA, 0.5\% Triton X-100, and Complete Protease Inhibitor (Roche), and the homogenate was incubated on ice for $30 \mathrm{~min}$. More details in the Supplementary Materials.

\subsection{Statistical Analysis}

Measurements were performed on a total of 12 animals for each group, analyzed in 2 different experimental sets (each experimental set was conducted on 6 animals) by researchers blinded to the treatment procedure. Results were expressed as means \pm S.E.M. (standard error of mean) of the two experiments and the analysis of variance was performed by one-way or two-way ANOVA tests (Figure 1, Figure 2 and Figure 4). A Bonferroni's significant difference procedure was used as a post hoc comparison, and $p$-values less than 0.05 were considered significant. Data were analyzed using the "Origin 8.1" software (Northampton, MA, USA). 

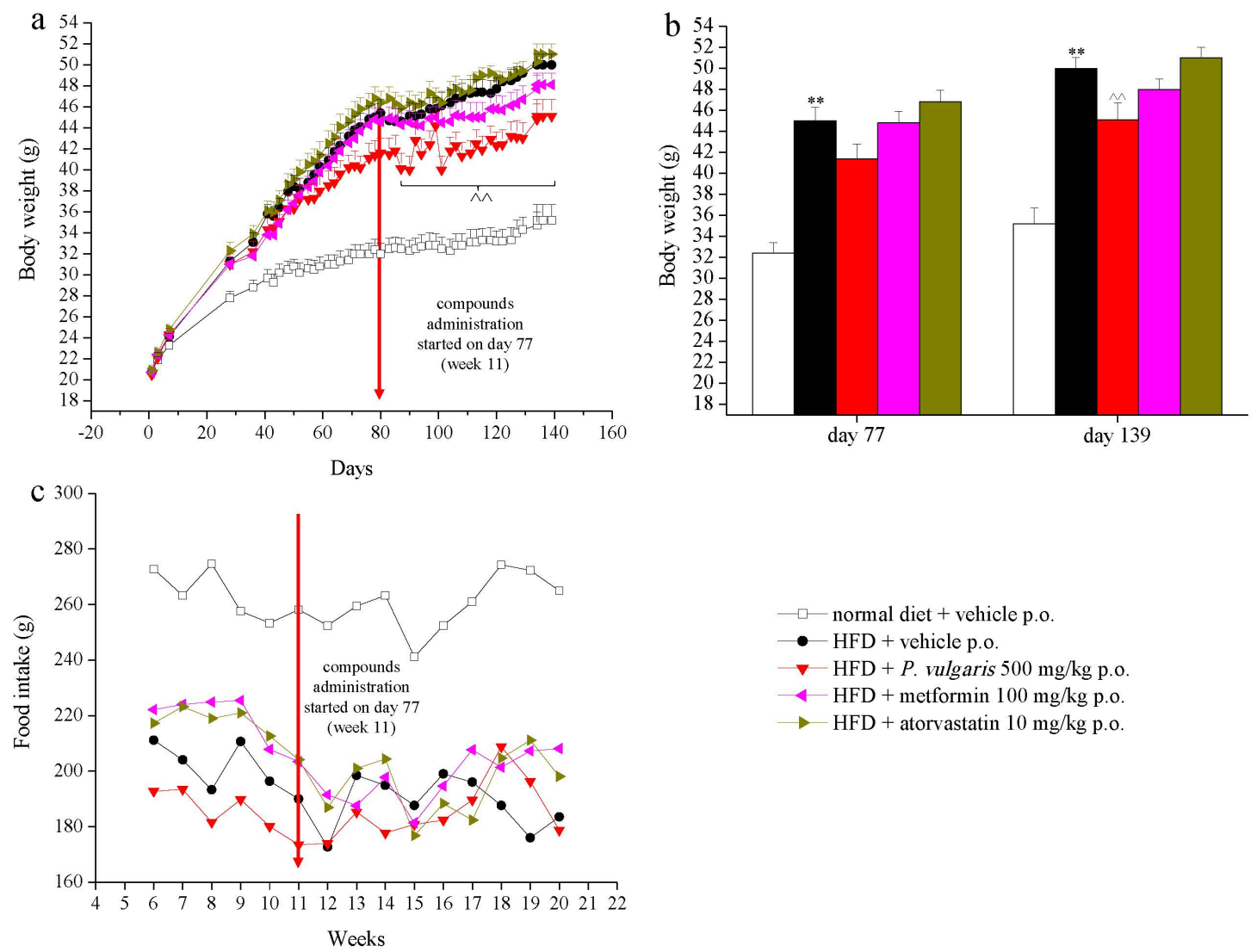

$\square-$ normal diet + vehicle p.o.

- HFD + vehicle p.o.

$\checkmark$ HFD $+P$. vulgaris $500 \mathrm{mg} / \mathrm{kg}$ p.o

4 HFD + metformin $100 \mathrm{mg} / \mathrm{kg}$ p.o.

$\rightarrow$ HFD + atorvastatin $10 \mathrm{mg} / \mathrm{kg}$ p.o.

Figure 1. Body weight and food intake. Mice were fed with a normal or a high fat diet (HFD) for 139 days. From day 77 (week 11), the animals were treated daily with vehicle (CMC 1\%), P. vulgaris extract $500 \mathrm{mg} / \mathrm{kg}$ per os (p.o.), metformin $100 \mathrm{mg} / \mathrm{kg}$ p.o., and atorvastatin $10 \mathrm{mg} / \mathrm{kg}$ p.o. (a,b) Animals' body weight evolution, and (c) Animals' food intake evolution. Red arrows point to the beginning of compound administration (day 77, week 11). Each value represents the mean \pm S.E.M. of 12 mice per group. ${ }^{* *} p<0.01$ vs. normal diet + vehicle; ${ }^{\wedge} p<0.01$ vs. HFD + vehicle. 

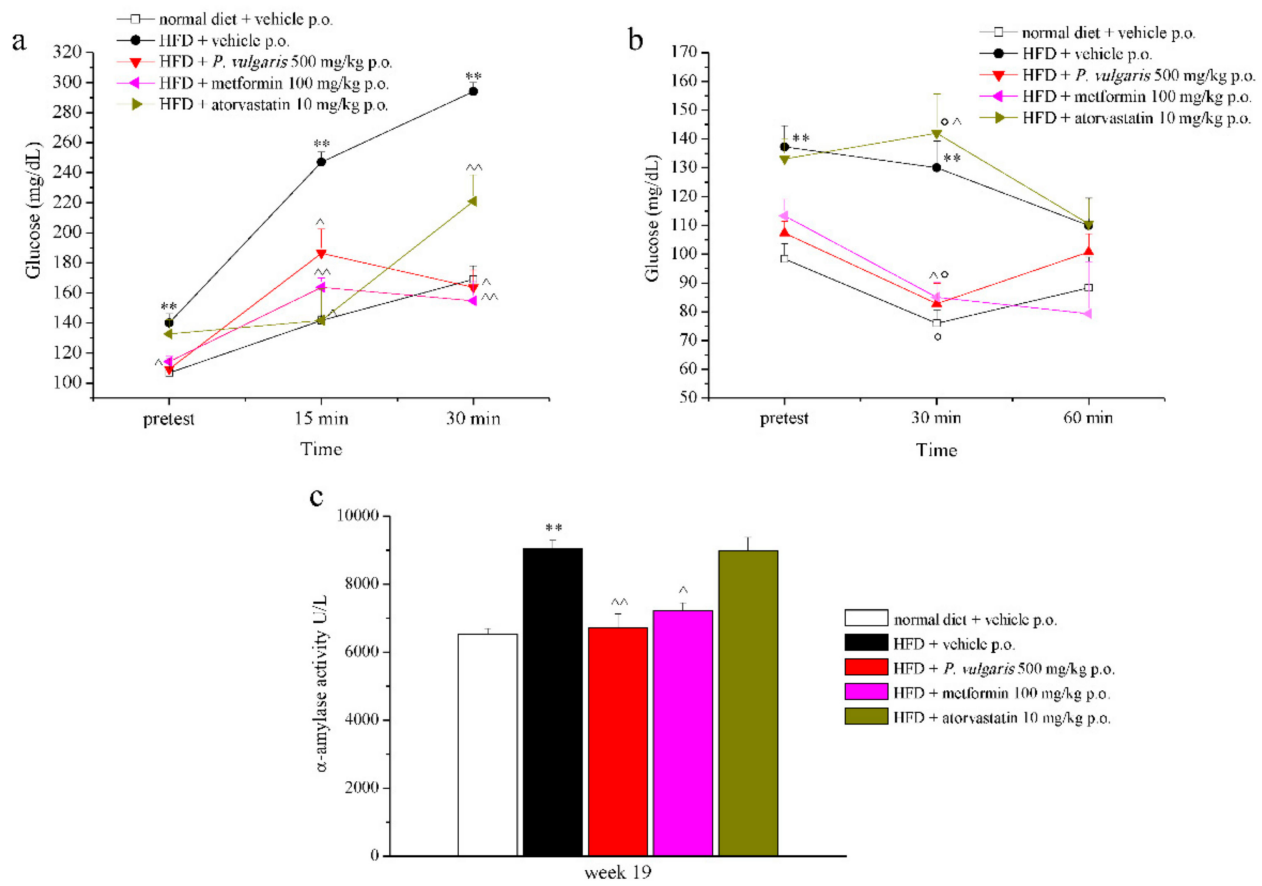

Figure 2. Glucose and insulin tolerance and $\alpha$-amylase activity. (a) Effects of HFD and treatments on glucose tolerance test at week 19; blood glucose was measured before the test (pre-test), and 15 and 30 min after the test. (b) Effects of HFD and treatments on insulin tolerance test at week 19. Glucose blood dosages were performed before the test (pre-test), and 30 and $60 \mathrm{~min}$ after the test. (c) Effects of HFD and treatments on the activity of $\alpha$-amylase (U/L) in plasmatic sample from animals at week 19. Each value represents the mean \pm S.E.M. of 12 mice per group. ${ }^{* *} p<0.01$ vs. group normal diet + vehicle; ${ }^{\wedge}$ $p<0.05$ and ${ }^{\wedge} p<0.01$ vs. HFD + vehicle; ${ }^{\circ} p<0.05$ vs. pre-test of the same group.

\section{Results}

\subsection{Treatments, Body Weight, and Food Intake}

C57BL/6 mice were fed with either a normal diet or a high fat diet (HFD) for 19 weeks. Throughout all this time, many parameters were periodically assessed: Body weight, food intake, hematic levels of glucose, triglycerides, and total cholesterol. From the eleventh week on, the mice fed with a high fat diet were divided into three groups and treated with P. vulgaris extract $500 \mathrm{mg} / \mathrm{kg}$, metformin $100 \mathrm{mg} / \mathrm{kg}$, and atorvastatin $10 \mathrm{mg} / \mathrm{kg}$. Control groups of both types of feeding were challenged with the vehicle alone (CMC 1\%). The drugs, the food extract, and the vehicle were administered daily per os (p.o.), $30 \mathrm{~min}$ before the dark phase of the circadian light/dark cycle of mice in the animal facility.

Figure 1a,b shows the effects of diet and treatments on body weight of each experimental group from the beginning of the feeding, with a normal or a high fat diet, until the end of the experiment. On day 0 , the body weight mean was homogeneous among all groups, but from day 28 a significant rise was evident in all groups fed with a HFD diet, with respect to the group fed with standard diet $(31.3 \pm 0.7 \mathrm{~g}$ vs. $27.8 \pm 0.6 \mathrm{~g}$, respectively). The body weight increase of HFD animals remained significant compared to control animals, from the first compounds challenge until the last experimental week. However, $P$. vulgaris extract administration induced a statistically significant weight reduction in HFD mice between day 85 (week 12) and day 139 (week 19) (Figure 1b), corresponding to an average $5 \mathrm{~g}$ loss in comparison with non-treated animals ( $47.3 \pm 0.36 \mathrm{~g}$ vs. $42.5 \pm 0.31 \mathrm{~g}$, respectively). Metformin treatment pointed out a reducing trend in body weight, but eventually it did not reach a statistical significance, while animals given atorvastatin did not show a different weight in comparison to the HFD diet control group (Figure 1b). 
Food intake was monitored weekly between the sixth and the 20th weeks (Figure 1c). The normal diet fed group consumed more food than the HFD animals, a trend which did not change throughout the whole experiment. Neither an increase nor a decrease in food intake was observed after week 11, the beginning week of treatments.

\subsection{Hematic Metabolic Parameters}

By this time, blood dosages of total cholesterol, triglycerides, and glucose were measured twice a month. Before the administration of the substances, the above-mentioned hematic parameters were significantly augmented in the high fat diet-fed animals, compared to the control animals (Supplementary Table S1).

In week 13, after two weeks of treatment, P. vulgaris extract and atorvastatin reduced total cholesterol levels by $24 \%$ and $30 \%$, respectively. This result was constant with statistical significance until the nineteenth week (Table 1). During these last seven days, HDL and LDL levels were also measured. The fat-enriched feeding did not alter HDL values in comparison to control animals, while it increased LDL levels, which were lowered by each treatment. The highest efficacy was reached by $P$. vulgaris extract treatments, which almost halved them.

Table 1. Hematic parameters.

\begin{tabular}{|c|c|c|c|c|c|c|}
\hline & & & & Group & & \\
\hline & Week & $\begin{array}{c}\text { Normal Diet }+ \\
\text { Vehicle }\end{array}$ & $\begin{array}{l}\text { HFD + } \\
\text { Vehicle }\end{array}$ & $\begin{array}{c}\text { HFD + } \\
\text { P. vulgaris }\end{array}$ & $\begin{array}{c}\text { HFD + } \\
\text { Metformin }\end{array}$ & $\begin{array}{c}\text { HFD + } \\
\text { Atorvastatin }\end{array}$ \\
\hline \multirow{4}{*}{ Glucose (mg/dL) } & 13 & $101.0 \pm 3.4$ & $139.3 \pm 6.9 *$ & $103.0 \pm 5.1^{\wedge}$ & $132.0 \pm 9.9$ & $133.0 \pm 6.2$ \\
\hline & 15 & $99.0 \pm 10.1$ & $149.5 \pm 3.9 * *$ & $103.0 \pm 8.0^{\wedge}$ & $113.3 \pm 7.4^{\wedge}$ & $112.8 \pm 7.1^{\wedge}$ \\
\hline & 17 & $103.3 \pm 6.4$ & $138.5 \pm 9.1 *$ & $127.8 \pm 2.0^{\wedge}$ & $121.0 \pm 5.9^{\wedge}$ & $146.3 \pm 5.5$ \\
\hline & 19 & $99.3 \pm 4.6$ & $137.3 \pm 9.4^{* *}$ & $112.0 \pm 4.4^{\wedge}$ & $116.3 \pm 5.7^{\wedge}$ & $137.3 \pm 14.0$ \\
\hline \multirow{4}{*}{$\begin{array}{l}\text { Triglycerides } \\
\text { (mg/dL) }\end{array}$} & 13 & $62.0 \pm 6.9$ & $132.3 \pm 11.3 *$ & $123.0 \pm 18.0$ & $105.0 \pm 14.6$ & $102.0 \pm 9.0^{\wedge}$ \\
\hline & 15 & $72.3 \pm 13.6$ & $135.3 \pm 6.0^{* *}$ & $86.5 \pm 10.7^{\wedge}$ & $93.3 \pm 10.4^{\wedge}$ & $103.3 \pm 9.4^{\wedge}$ \\
\hline & 17 & $78.4 \pm 2.7$ & $136.8 \pm 2.3^{* *}$ & $105.3 \pm 7.8^{\wedge}$ & $113.8 \pm 5.8^{\wedge}$ & $108.8 \pm 7.2^{\wedge}$ \\
\hline & 19 & $75.8 \pm 11.0$ & $133.5 \pm 7.7^{* *}$ & $107.5 \pm 9.3^{\wedge}$ & $118.3 \pm 3.7$ & $104.0 \pm 3.0^{\wedge}$ \\
\hline \multirow{4}{*}{$\begin{array}{l}\text { Total cholesterol } \\
\text { (mg/dL) }\end{array}$} & 13 & $<100$ & $133.7 \pm 4.4^{* *}$ & $104.3 \pm 3.5^{\wedge}$ & $128.6 \pm 8.2$ & $105.0 \pm 6.0^{\wedge}$ \\
\hline & 15 & $105.0 \pm 5.0$ & $135.8 \pm 1.3^{* *}$ & $103.0 \pm 2.3^{\wedge}$ & $118.3 \pm 7.2$ & $105.0 \pm 4.3^{\wedge}$ \\
\hline & 17 & $107.0 \pm 1.2$ & $147.0 \pm 2.8^{* *}$ & $123.0 \pm 6.4^{\wedge}$ & $139.3 \pm 12.5$ & $109.5 \pm 5.0^{\wedge}$ \\
\hline & 19 & $103.8 \pm 4.1$ & $147.3 \pm 4.1^{* *}$ & $100.5 \pm 7.6^{\wedge}$ & $103.9 \pm 9.2^{\varkappa}$ & $76.4 \pm 1.4^{\wedge}$ \\
\hline HDL (mg/dL) & 19 & $51.8 \pm 8.5$ & $62.3 \pm 7.0$ & $41.7 \pm 10.2$ & $59.1 \pm 10.5$ & $46.8 \pm 9.5$ \\
\hline $\begin{array}{c}\text { LDL } \\
(\mathrm{mg} / \mathrm{dL})\end{array}$ & 19 & $43.8 \pm 6.7$ & $62.3 \pm 7.0$ & $38.4 \pm 6.3^{\wedge}$ & $46.0 \pm 9.4^{\wedge}$ & $50.2 \pm 3.0^{\wedge}$ \\
\hline
\end{tabular}

Effects of HFD and treatments on glucose, triglycerides, and total cholesterol blood concentration at weeks 13, 15, 17, and 19. At week 19, HDL and LDL values were also assessed. Animals were fed with normal or HFD diets from week 1. P. vulgaris extract $(500 \mathrm{mg} / \mathrm{kg})$, metformin $(100 \mathrm{mg} / \mathrm{kg})$, and atorvastatin $(10 \mathrm{mg} / \mathrm{kg})$ were administered daily per os, starting from week 11. Each value represents the mean \pm S.E.M. of at least 12 mice per group. ${ }^{*} p<0.05$ and $* * p<0.01$ vs. normal diet + vehicle; ${ }^{\wedge} p<0.05$ and ${ }^{\wedge} p<0.01$ vs. HFD + vehicle.

Triglycerides were lowered from the first challenge only by atorvastatin (by 22\%), while P. vulgaris and metformin administrations began to be effective from week 15, until week 19 and week 17, respectively, inducing results similar to those obtained by atorvastatin injections (Table 1). As to hematic glucose levels, they were reduced by the administration of P. vulgaris extract and metformin, by about a fifth and a sixth, respectively. Atorvastatin appeared to be non-effective (Table 1).

\subsection{Glucose and Insulin Tolerance Test}

The results of the glucose tolerance test (GTT) performed at week 19 are displayed in Figure 2a. Glucose tolerance is shown by the HFD control animals, whose maximum glycaemic peak, reached $30 \mathrm{~min}$ after sugar administration (1 g/kg p.o.), was $294.0 \pm 5.9 \mathrm{mg} / \mathrm{dL}$. A reduction of hematic glycaemia was observed in the treated groups, at all times of the experiment. Indeed, 30 min after the 
beginning of the test, glucose levels of $P$. vulgaris extract, atorvastatin, and metformin-treated mice were similar to those of normal diet control mice, while this value almost doubled in non-treated HFD group. Next to the glucose tolerance test, the insulin tolerance test (ITT) was also performed at week 19 (Figure $2 b$ ). High fat diet-fed animals were resistant to insulin injection (1U/kg i.p.), as demonstrated by stable glycaemic values 30 and 60 min following the administration, in comparison with the pre-test. A slight, non-significant delayed response to insulin of HFD animals can be highlighted. The groups treated with P. vulgaris extract and metformin were sensitive to the hormonal hypoglycaemic activity, as explained by the reduced glycaemic values with respect to both the pre-test and the 30 min dosages of the HFD controls. In the latter comparison, a one third reduction was observed, while in the first comparison, there was a $22 \%$ and a $25 \%$ decrease due to P. vulgaris extract and metformin, respectively. Atorvastatin treatment did not lower the tolerance to the insulin induced by high fat diet. The evaluations of GTT and ITT were performed on fed animals according to the literature which shows that the measure of glucose concentrations in fed state mice is informative as well as the measure performed in fasted animal [28]. The values of the area under the curve (AUC) for GTT and ITT were reported in Supplementary Table S2. The HOMA-IR values were also calculated and are reported in Supplementary Table S3.

\subsection{Plasma Enzymatic and Oxidative Parameters}

During the last experimental week, insulin and ghrelin plasmic levels were measured. Insulin was higher in HFD non-treated with respect to control animals. P. vulgaris extract and metformin lowered that value in a significant way by about $80 \%$ (Table 2). Ghrelin plasmic values also appeared to be altered in animals on high fat diet with respect to the control animals $(10.5 \pm 3.4 \mathrm{ng} / \mathrm{mL}$ vs. $38.6 \pm 5.8 \mathrm{ng} / \mathrm{mL}$, respectively), and under treatment there was a trend to increase, but with no significance (Table 2). Then, plasmatic alpha-amylase enzymatic activity was measured (Figure 2c). The fat-enriched diet positively modulated enzyme activity with respect to the control levels, as it was almost unvaried in $P$. vulgaris extract and metformin-treated groups. Atorvastatin administration was not able to lower the high values induced by the high fat diet.

Table 2. Insulin and ghrelin levels.

\begin{tabular}{|c|c|c|c|c|c|}
\hline & \multicolumn{5}{|c|}{ Group } \\
\hline & $\begin{array}{c}\text { Normal Diet + } \\
\text { Vehicle }\end{array}$ & HFD + Vehicle & $\begin{array}{c}\text { HFD + } \\
\text { P. vulgaris }\end{array}$ & $\begin{array}{c}\text { HFD + } \\
\text { Metformin }\end{array}$ & $\begin{array}{c}\text { HFD + } \\
\text { Atorvastatin }\end{array}$ \\
\hline $\begin{array}{l}\text { Insulin } \\
\text { (ng/mL) }\end{array}$ & $4.2 \pm 0.5$ & $46.1 \pm 7.3^{* *}$ & $8.9 \pm 8.2^{\wedge}$ & $10.2 \pm 7.6^{\wedge}$ & $34.9 \pm 10.5$ \\
\hline $\begin{array}{l}\text { Ghrelin } \\
(\mathrm{ng} / \mathrm{mL})\end{array}$ & $38.6 \pm 5.8$ & $10.5 \pm 3.4^{*}$ & $17.0 \pm 2.8$ & $13.8 \pm 4.3$ & $15.8 \pm 2.4$ \\
\hline
\end{tabular}

Effects of HFD and treatments on insulin and ghrelin plasma concentration at week 19. At week 19, HDL and LDL values were also assessed. Animals were fed with normal or HFD diets from week 1. P. vulgaris extract $(500 \mathrm{mg} / \mathrm{kg})$, metformin $(100 \mathrm{mg} / \mathrm{kg})$, and atorvastatin $(10 \mathrm{mg} / \mathrm{kg})$ were administered daily per os starting from week 11 . Each value represents the mean \pm S.E.M. of at least 12 mice per group. ${ }^{*} p<0.05$ and ${ }^{* *} p<0.01$ vs. normal diet + vehicle; ${ }^{\wedge} p<0.01$ vs. HFD + vehicle.

Another parameter measured from plasma was protein carbonylation (Figure 3), which was evaluated as integrated density (Figure 3a) from Western blot membranes (Figure 3b). Plasma from HFD mice had a $45 \%$ increase of carbonylated proteins than plasma from control animals. That value was reduced nearly to the control levels by chronic treatment with $P$. vulgaris extract. 
a

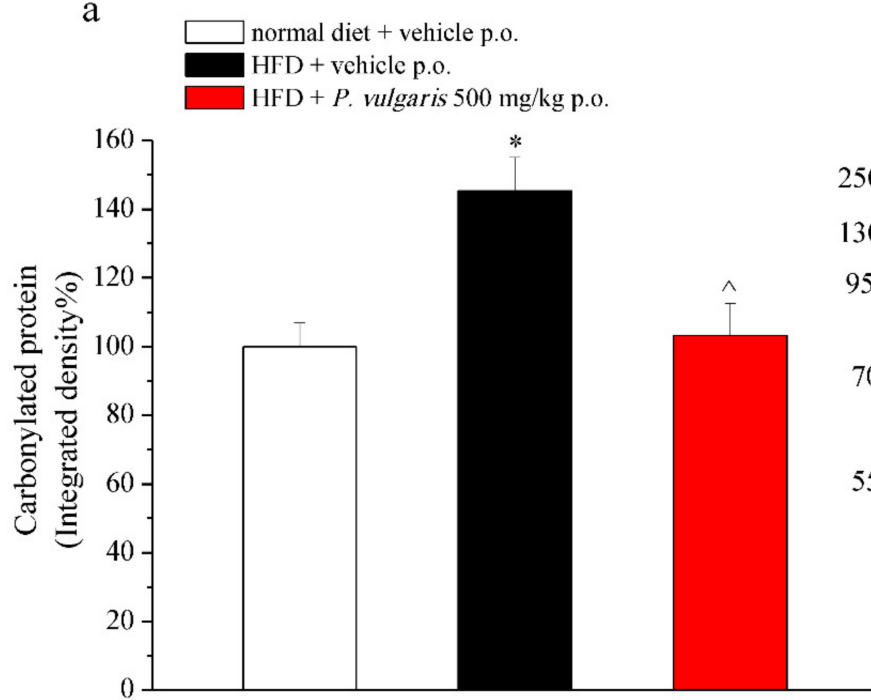

b

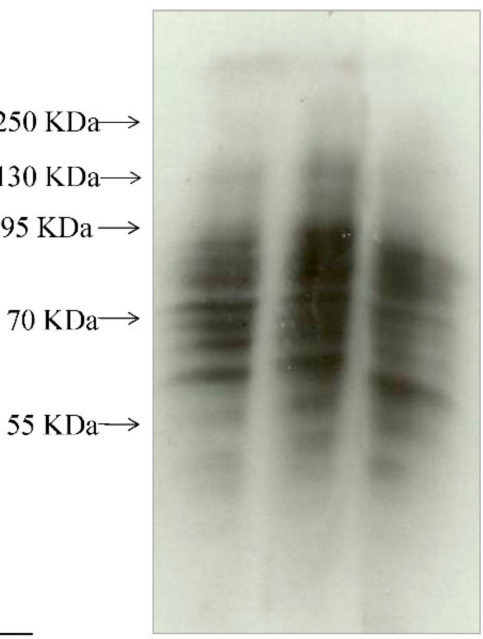

Figure 3. Plasmatic oxidation. Effects of HFD and treatments on the levels of carbonylated proteins in plasma (week 19). Protein oxidative damage was quantified by immunoblot. (a) Densitometric analysis and (b) representative Western blot are shown. Ponceau-stained membranes were used as loading control. Results are expressed as \% of control group (normal diet + vehicle; $100 \%$ ). Each value represents the mean \pm S.E.M. of 12 mice per group. ${ }^{*} p<0.05$ vs. normal diet + vehicle; ${ }^{\wedge} p<0.05$ vs. HFD + vehicle.

\subsection{Behavioral Measurements}

On week 19, behavioral measurements were also made, in order to highlight motorial and neurological alterations due to the fat-enriched diet.

The Rota Rod test (Figure 4a) was used to evaluate motor coordination. The HFD animals fell from two to three times more than the control animals throughout the one-hour exercise. Among all the treatments, only P. vulgaris extract had restoring effects, making mice fall the same number of times as the control animals. The Von Frey test evaluated mechanical allodynia evoked by a non-noxious stimulus (Figure 4b). As shown by the graph, HFD mice demonstrated a significantly lowered nociceptive threshold with respect to the control animals $(1.2 \pm 0.03 \mathrm{~g}$ vs. $1.5 \pm 0.03 \mathrm{~g}$, respectively). Again, $P$. vulgaris extract treatment reverted this pain condition to the control threshold. Other two behavioral tests, the plantar test (Supplementary Table S4) and the elevated plus maze test (Supplementary Table S5), did not show significant alterations between the two control groups. 
a

$\square-$ normal diet + vehicle p.o.
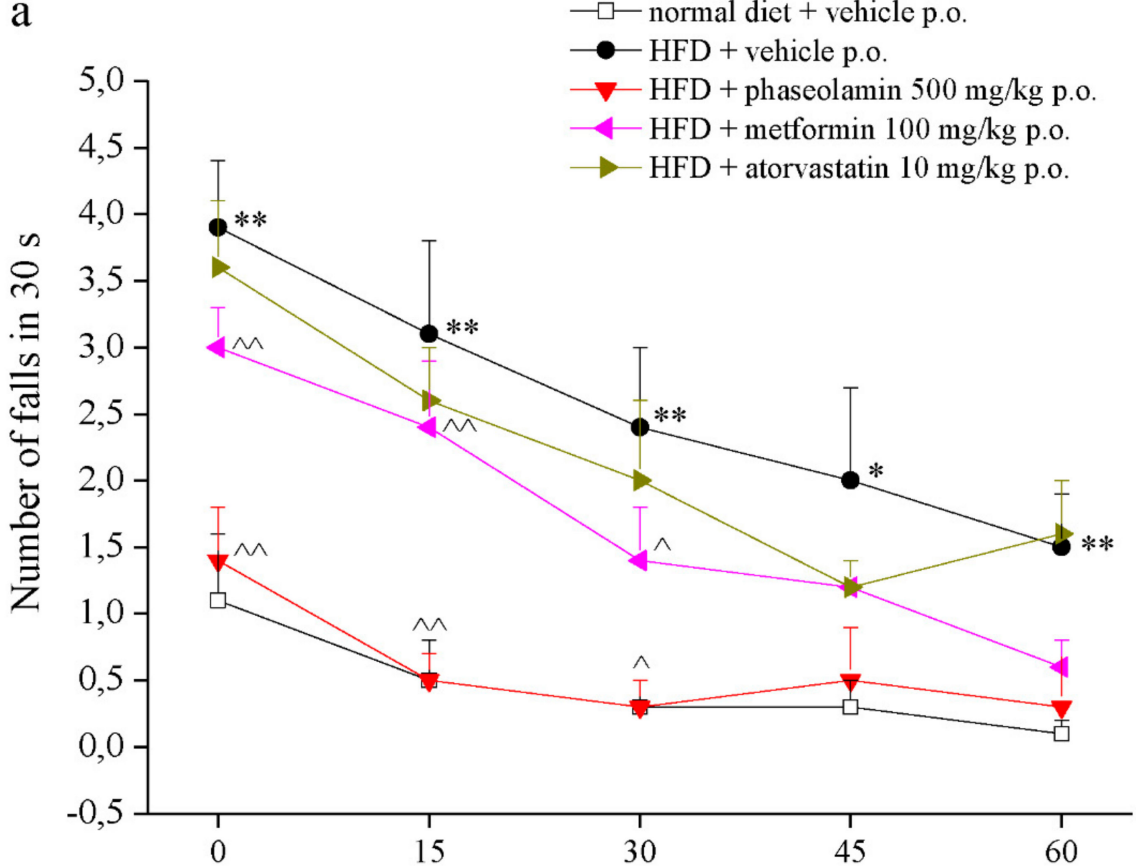

b

Time (min)

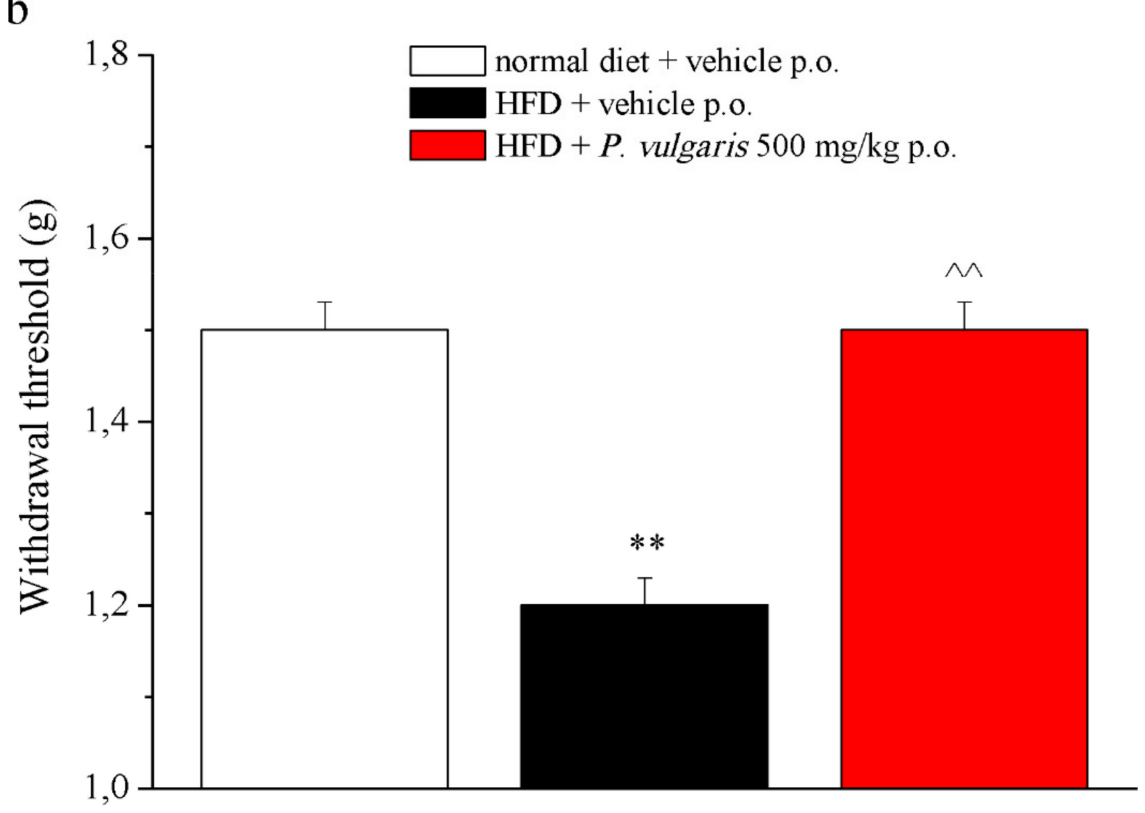

Figure 4. Behavior. (a) The integrity of the animals' motor coordination (week 19) was assessed using a rota-rod apparatus. Rats were placed on a rotating rod (10 rpm) for $30 \mathrm{~s}$ every $15 \mathrm{~min}$ for $1 \mathrm{~h}$. The number of falls was counted. (b) The pain threshold was measured by the Von Frey test to assess the response evoked by a mechanical non-noxious stimulus. Each value represents the mean \pm S.E.M. of 12 mice per group. ${ }^{*} p<0.05$ and ${ }^{* *} p<0.01$ vs. normal diet + vehicle; $^{\wedge} p<0.05$ and ${ }^{\wedge} p<0.01$ vs. HFD + vehicle. 


\subsection{Ex Vivo Analysis}

At the end of the nineteenth week, the animals were sacrificed and some of their organs were explanted for subsequent ex vivo analysis.

The heart, the liver, and the brain were weighed: the heart and the liver of non-treated HFD mice had a higher weight than the organs of mice fed with a normal diet (Figure 5a,b). The administration of $P$. vulgaris extract reduced the weight gain of the heart and liver ensuing the fat-enriched diet, reaching a weight highly close to that of the control mice organs. Tissue weight of the liver, but not the heart, was brought down also by metformin and atorvastatin administrations, but in a less remarkable way than the food extract did: the latter reduced the weight by $40 \%$, the drugs only by 30 and 20 percent, respectively (Figure 5b). As to the brain, no significant alterations were observed when comparing tissue weight of the different experimental groups (Supplementary Figure S1).
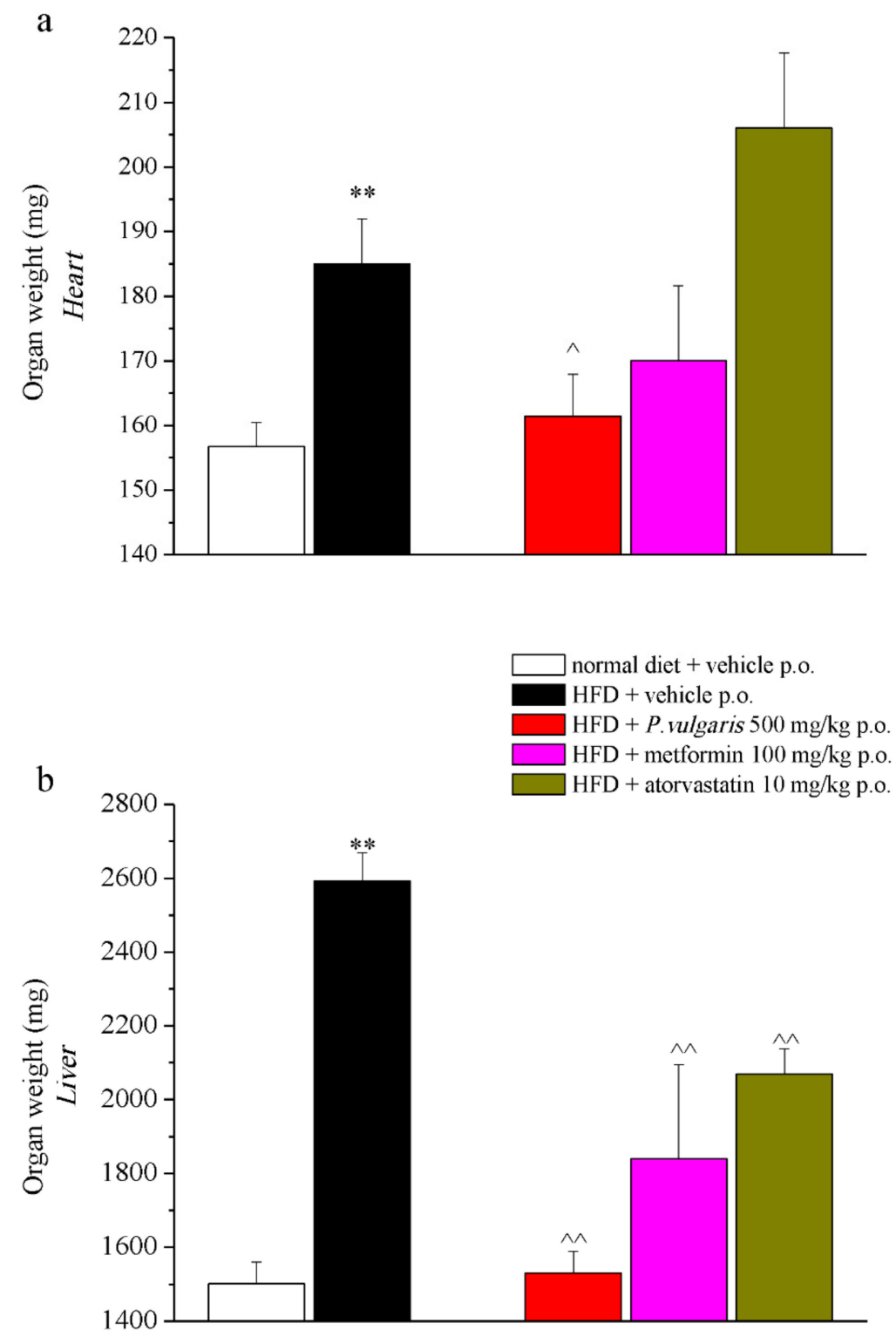

Figure 5. Organ weight. An week 19, after in vivo examinations, organs were collected and weighed. (a) Heart; (b) liver. Each value represents the mean \pm S.E.M. of 12 mice per group. ${ }^{* *} p<0.01$ vs. normal diet + vehicle; ${ }^{\wedge} p<0.05$ and ${ }^{\wedge} p<0.01$ vs. HFD + vehicle. 
Other histological and quantitative examinations were performed on the explanted tissues. As is shown in Figure 6a, the hypercaloric diet caused a diffuse steatosis in the hepatic parenchyma, not present in the liver of normal diet-fed mice. The pathological state was also expressed in numbers by the steatosis index, as $9.66 \pm 0.33$ vs. $0.5 \pm 0.1$, referring to HFD and control mice, respectively (Figure 6b). Another liver damage parameter to be evaluated was lipid peroxidation, expressed as micromoles of thiobarbituric acid reactive substances (TBARS) per milligrams of protein present in the sample. Feeding with fat-rich food caused a $40 \%$ more oxidative state of the lipidic component in comparison to the control, while P. vulgaris extract treatment avoided the lipid peroxidation increase, whose state was maintained similar to the control levels (Figure 6c).

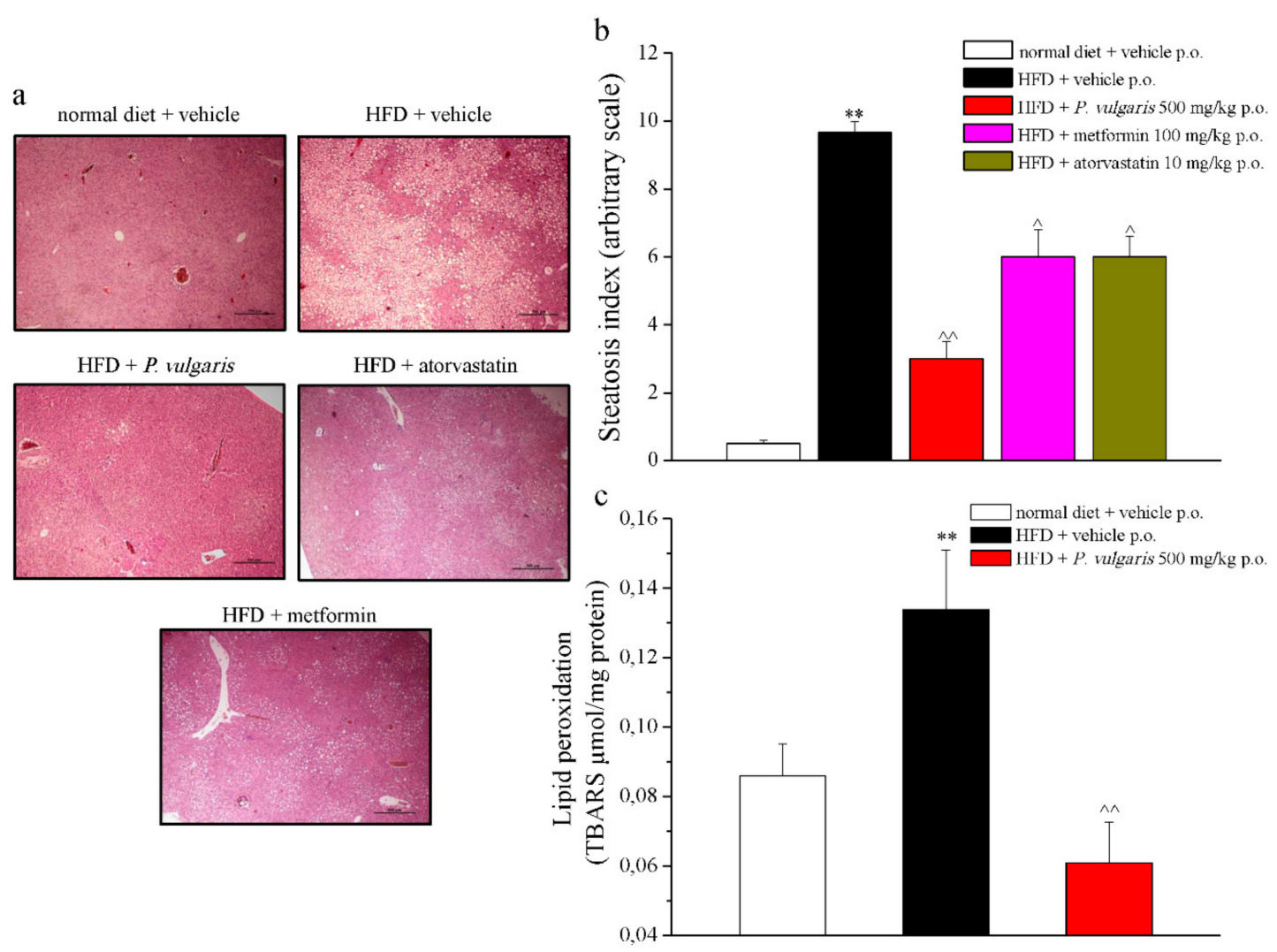

Figure 6. Liver damage parameters. (a) Representative images of paraffin-embedded liver sections (5 $\mu \mathrm{m}$ thickness), stained with hematoxyllin-eosin, 4X magnificated. (b) Quantitative expression of steatosis index (graded ' 0 ' to ' 10 ' based on the average percent of fat-accumulated, $0<5 \%, 10>75 \%$ ). (c) Oxidative alteration. Lipid peroxidation was evaluated measuring TBARS ( $\mu \mathrm{mol} / \mathrm{mg}$ protein). Week 19. Each value represents the mean \pm S.E.M. of 12 mice per group. ${ }^{* *} p<0.01$ vs. normal diet + vehicle; ${ }^{\wedge} p<0.05$ and ${ }^{\wedge} p<0.01$ vs. HFD + vehicle. 
In Figure 7, four cardiac damage parameters are illustrated: the expression of catalase enzyme (7a), glutathione reductase enzyme (7b), NADH dehydrogenase enzyme (7c), and the level of protein carbonylation (7d). Catalase enzyme expression, involved in the detoxification of hydrogen peroxide, appeared to be increased by $62 \%$ in the hearts of HFD mice and by $200 \%$ in those of HFD mice challenged with P. vulgaris extract, in comparison with the control hearts. As to glutathione reductase, which reduces oxidized endogen glutathione, its expression was positively modulated by a high fat diet and by P. vulgaris extract administration. In the graph, the integrated density calculation showed a $23 \%$ increased expression in the hearts of HFD mice and an 180\% increase in those of HFD P. vulgaris extract-treated mice. The third analyzed enzyme was NADH dehydrogenase, also named Complex I, which transfers electrons from NADH to an acceptor in the mitochondrial respiratory chain. The results show that the prolonged alimentation with high fat food stimulated a significative increase of the enzyme expression with respect to the control. The integrated density calculated on heart samples of the HFD animals increased by $120 \%$, compared to the control. A decreasing trend, but not statistically significant, was observed when the animals were challenged with $P$. vulgaris extract. Eventually, protein carbonylation dosage gave a measure of the oxidative stress state of the heart. Carbonylated proteins were $45 \%$ more in the heart of the HFD animals, compared to the control animals, a condition which was not reduced in a significant way by $P$. vulgaris extract administration.
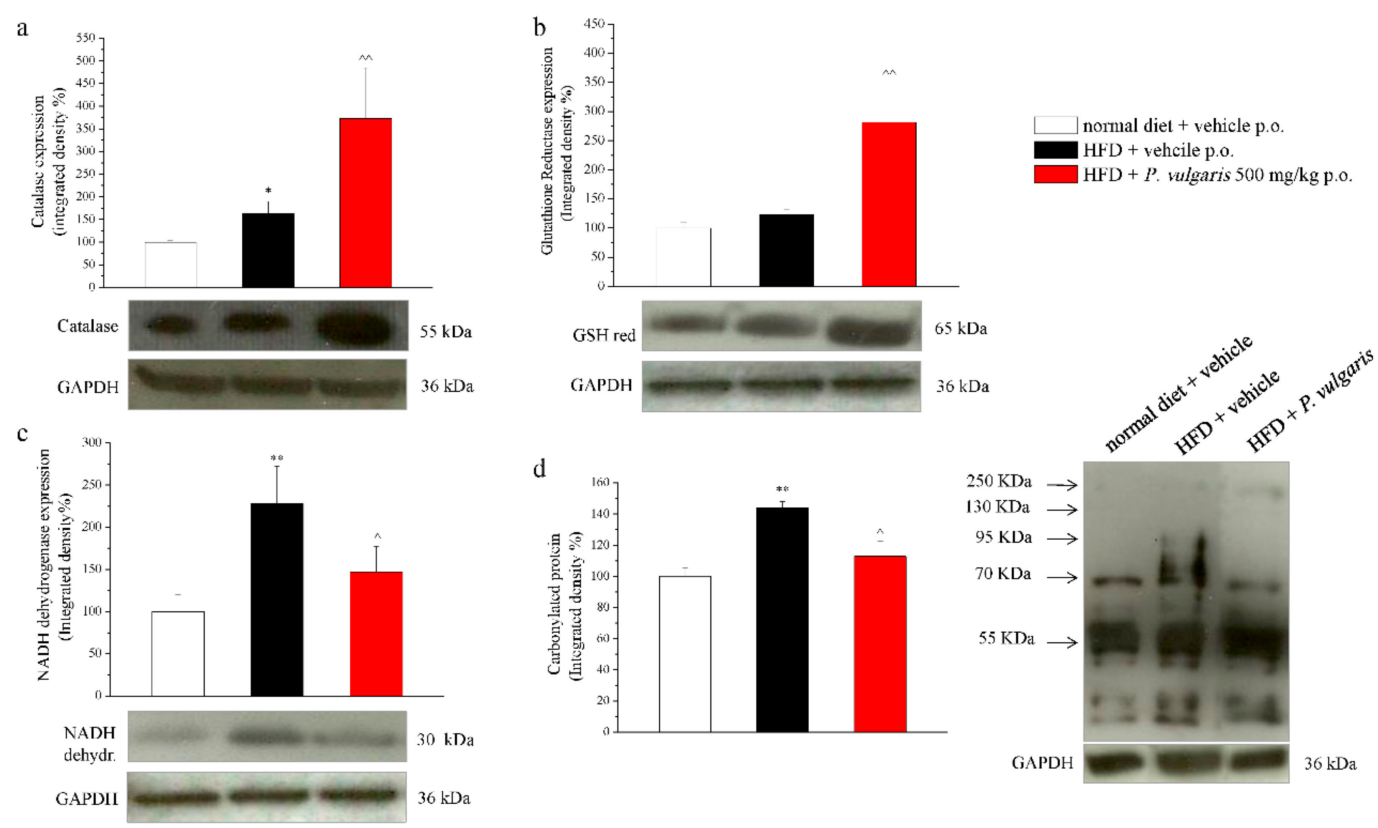

Figure 7. Cardiac damage parameters. Tissue homogenate was processed by Western blot in order to evaluate the protein expression of (a) catalase; (b) glutathione reductase; (c) NADH dehydrogenase; and (d) carbonylated proteins. Each parameter is reported as representative blot and densitometric analysis. GAPDH normalization was performed for each sample. Results are expressed as \% of control group (normal diet + vehicle; $100 \%$ ). Week 19. Each value represents the mean \pm S.E.M. of 12 mice per group. ${ }^{*} p<0.05$ and ${ }^{* *} p<0.01$ vs. normal diet + vehicle; ${ }^{\wedge} p<0.05$ and ${ }^{\wedge} p<0.01$ vs. HFD + vehicle. 
Next to the cardiac parameters, vascular system condition was also controlled. Oil Red O staining made it possible to evaluate lipidic infiltrations in the aortic muscular layers (Figure 8a-d). HFD feeding extensively augmented lipid infiltration in the aortic tissue, rather than normal alimentation did $(879 \pm 66 \%$ vs $100 \pm 15 \%$, respectively). Sustained $P$. vulgaris challenges more than halved the lipid deposit built up by high calories feeding.

Histological analysis was also made on epidydimal white adipose tissue. The photomicrographs represent the effect of fat-enriched alimentation on the area of the adipocytes: The HFD adipocyte mean area doubled the control mean area and P. vulgaris extract treatment did not lower significantly the adipocyte enlargement (Figure $9 \mathrm{a}-\mathrm{d}$ ).
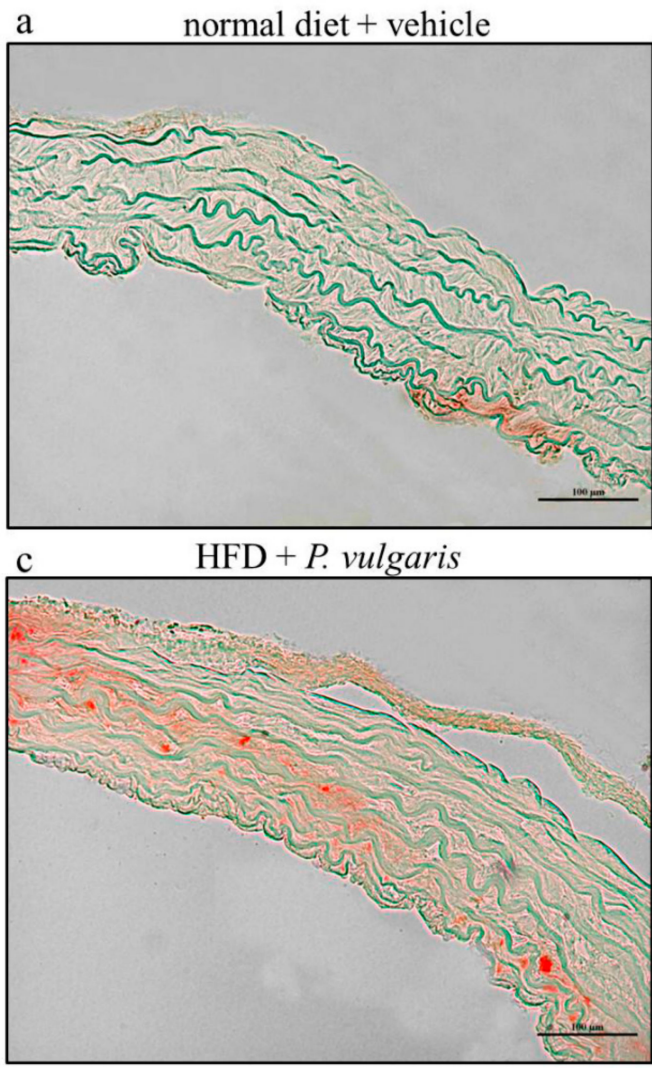

b

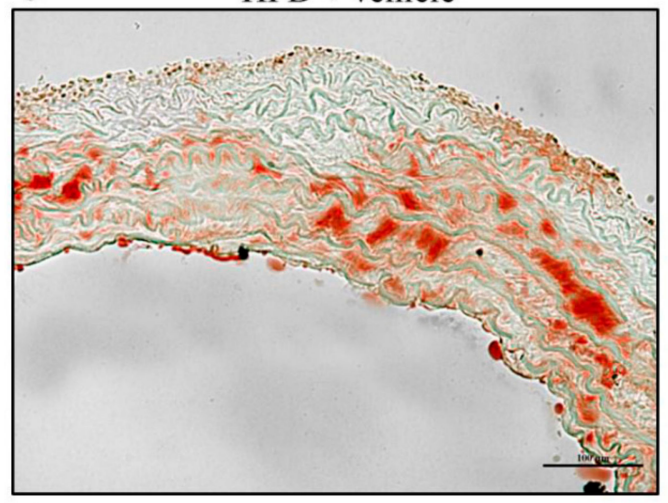

d

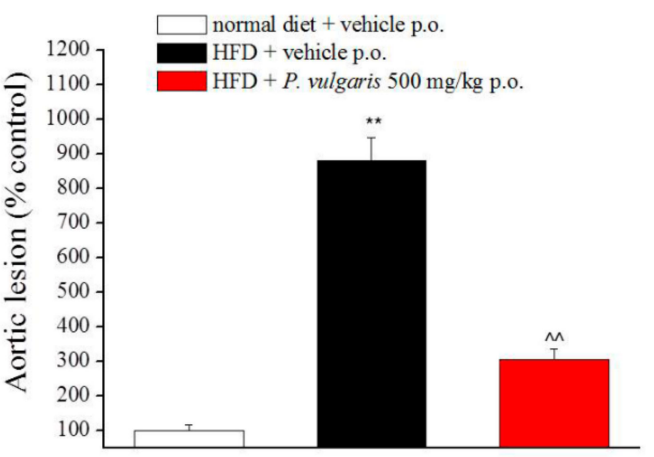

Figure 8. Vascular damage. (a-d) Evaluation of fatty streak infiltrations in aortic tissue of animals an week 19. (a,b,d) Representative images of aortic arch sections stained with Oil-Red O, 20X magnificated. (d) Quantitative determination of lesion extension, calculated as the positive area in comparison to the total cross-sectional vessel wall area. Aortic damage is expressed as percentage in comparison to control samples (set as 100\%). ${ }^{* *} p<0.01$ vs. normal diet + vehicle; ${ }^{\wedge} p<0.01$ vs. HFD + vehicle. 

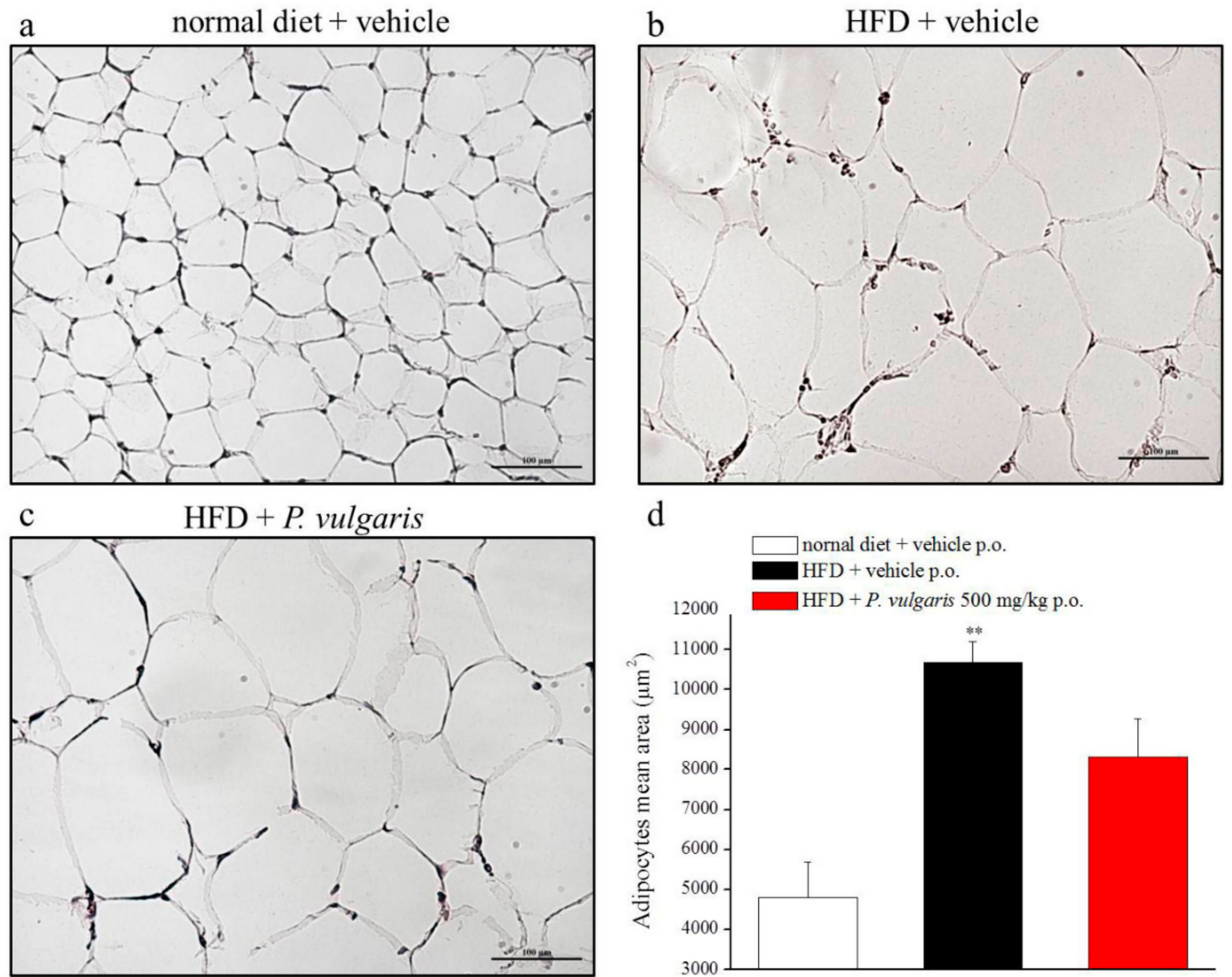

d

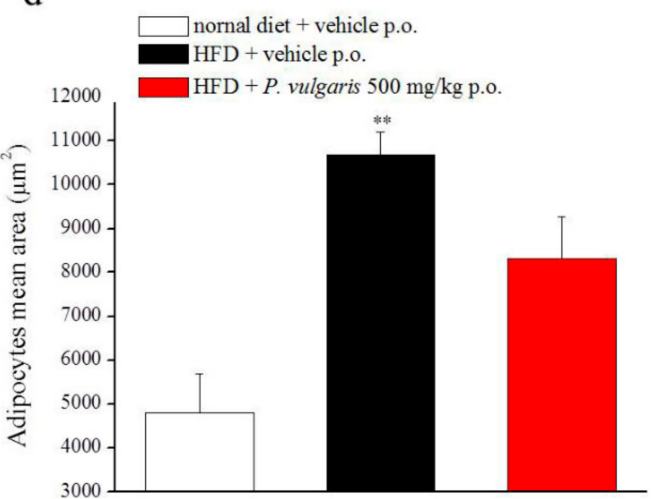

Figure 9. Adipose tissue damage. (a-d) Effects of diet and P. vulgaris treatment on white adipose tissue. $(\mathbf{a}-\mathbf{c})$ Representative images of subcutaneous adipose tissue sections stained with hematoxylin-eosin, 20X magnificated. (d) Quantitative determination of adipocytes mean area $\left(\mu \mathrm{m}^{2}\right)$ following HFD or $P$. vulgaris administration. Each value represents the mean \pm S.E.M. of 12 mice per group. ${ }^{* *} p<0.01$ vs. normal diet + vehicle.

Morphologic analysis of renal tissue did not highlight any pathologic alteration between the two differently fed group of animals: Both glomerular and mesangial regions showed unvaried area measures with respect to the control (Supplementary Figure S2).

\section{Discussion}

The relevance of metabolic syndrome is due to the severity of the disorders that it involves: Hyperglycaemia, insulin resistance, dyslipidaemia, obesity, atherogenic events, and hepatic steatosis. All these hallmarks can easily lead to the onset of type 2 diabetes and cardiovascular problems. Therefore, there is a real need for drugs able to target one or more of these disturbs, with few minor side effects.

In the present study, we successfully produced a murine model of metabolic syndrome, in which we investigated the protective effects of a standardized extract from $P$. vulgaris seeds. Its activity was compared with two reference drugs, metformin and atorvastatin, that are used in clinical for the management of hyperglycaemia and hypercholesterolemia, respectively. We obtained highly encouraging results, as we demonstrated that the natural substance equalled and even sometimes outdid the reference drug beneficial effects. The originality of our work consists in the evaluation of the effect of an eight week daily treatment with a $P$. vulgaris extract on all hallmarks of metabolic syndrome, ranging from the effect on blood glucose, triglycerides and cholesterol levels to the effect on pain and motor alteration to the ex vivo analysis. We investigated the protective effect of $P$. vulgaris extract repeated treatment on liver steatosis, on vascular damage, and on oxidative stress, highlighting that the mechanism of action of $P$. vulgaris is due to its constituent phaseolamin, an alpha-amylase inhibitor. 
The onset of the syndrome was induced by high fat diet (HFD) feeding, containing 60\% fats out of the total calories, composed by animal fat and sucrose. The first induces metabolic disorders more effectively than vegetable fat does, while the second exacerbates the correlated negative outcomes, above all dyslipidaemia [29].

We firstly showed that $P$. vulgaris extract treatment significantly prevented the weight gain in HFD mice, even more than treatment with the reference drugs. Several works on $P$. vulgaris extract reported this anorexigenic effect, on diabetic and healthy rats, following acute or chronic administration in ranging doses of 50-500 mg/kg. In such cases, it was supported by a concomitant reduction in food intake $[30,31]$, a condition which we did not observe. A cholecystokinin-mediated mechanism was suggested [30] to explain the food intake decrease, nevertheless Reverri et al. [32] showed that the increased plasmatic concentration of cholecystokinin in human subjects treated with a meal enriched with black bean did not produce the expected heightened satiety.

Weight loss can be explained as independent of food intake: Fat reserves of HFD mice could have been mobilized due to reduced total energy in form of glucose, whose plasmatic level was lowered under treatment $[17,33,34]$. Some decades after its discovery, the alpha amylase inhibitor-1 phaseolamin was tested for anti-obesity starch-blocker effects on humans: Even if a significant weight loss in obese and healthy subjects treated with the commercial $\alpha \mathrm{AI} 1$ extract Phase $2^{\mathrm{TM}}$ was reported, in other trials different commercial phaseolamin-based starch-blockers did not influence body weight. Therefore, one could state that the anorexigenic effect is probably related to the maintenance of elevated enzymatic anti-amylase activity and purity level of the compound, which in turn depends on extraction and preparation methods of the starch-blocker commercial product [7].

We demonstrated that chronical administration of a $P$. vulgaris extract, containing alpha-amylase inhibitor and phyto-haemagglutinin, had alleviating effects on three hallmarks of metabolic syndrome: Hypercholesterolemia, hypertriglyceridemia, and hyperglycaemia. P. vulgaris extract behaved as a hypocholesterolemic agent on HFD mice soon after two weeks of treatment: It produced results similar to those obtained by the reference drug atorvastatin; moreover, it was the most efficient compound for decreasing LDL values during the last experimental week, suggesting an increasing protective effect. Similar studies on the bioactive natural compound, carried out on diabetic rats, did not highlight any significant change in cholesterol levels [11], but a clinical open-label study on ten overweight and hypercholesterolemic patients underlined a remarkable decrease of total cholesterol following a prolonged treatment with granular food containing the P. vulgaris dry extract mixed with other bioactive compounds [35]. A study conducted by Nunez-Aragon and colleagues indicated that total hydrolysates and $<1 \mathrm{kDa}$ fractions from $P$. vulgaris showed antihyperglycemic activity, and this activity was due to intestinal glucose absorption and $\alpha$-glucosidase enzyme inhibition and was safe up to $5000 \mathrm{mg} \mathrm{kg}^{-1}$. Bean-derived protein hydrolysates and fractions may therefore have the potential to be used in functional foods, dietary supplements, or pharmaceutical preparations for the prevention and/or treatment of type 2 diabetes [36].

The beneficial effect of $P$. vulgaris extract treatment on blood triglycerides outdid the hypolipidemic activity of metformin and equalled that of atorvastatin, effective a couple of weeks before the extract and metformin.

The kidney extract was protective against hyperglycaemia, a result consistent with many studies on rats (diabetic or healthy, fed with normal or starch-enriched diet), where different quantities of the $\alpha$-amylase inhibitor, chronically administrated from 10 to 20 days, induced a significant reduction of glucose blood levels at the end of the prolonged treatment. In addition, when acutely administrated, this lowering effect was observed on the post-prandial glycaemia levels, even if not always statistically significant $[17,33,34]$. The efficacy on post-prandial hyperglycaemia was confirmed in humans by a study of Spadafranca and her collaborators on healthy men and women, who were given a tablet of P. vulgaris extract (containing both $\alpha$-AI and phytohaemagglutinin; the same used in the present study) to be ingested before a standardized meal [37]. Obesity is not only a matter of weight gain, but behind that there are many other factors which predispose to diabetes and cardiovascular 
diseases. A low-grade chronic inflammation ensues the pro-inflammatory activity of obesity-induced hypertrophied adipocytes and inflammatory cells, and along with increased free fatty acids they alter insulin receptor pathway, till its inhibition [38]. In our study, the HFD provoked an impaired response to both glucose and insulin, confirming the two typical resistance forms of metabolic syndrome. We showed that $P$. vulgaris extract treatment significantly alleviated both tolerances; metformin showed a similar profile, whereas atorvastatin was effective in preventing the altered response to glucose load only. Insulin hormone is crucial in glucose and lipid metabolism and it is also related to the satiety pathway of central and peripheral nervous system: A hampered response of the nervous insulin receptors was reported to be related to appetite control, leading to hyperphagia and obesity. In addition, chronic hyperinsulinemia generally occurring in obese patients appears to function as a compensatory strategy of our organism, in order to restore energy reserves and to limit weight gain [39]. In our experiments, HFD mice at the 19th week of the enriched diet had high insulin plasmatic levels remarkably lowered by $P$. vulgaris extract and metformin treatment, in an almost identical way.

Ghrelin is another hormone thought to have a prominent role in obesity and metabolic syndrome. Ghrelin is a stomach-derived peptide hormone, produced by the endocrine cells of the oxyntic mucosa, which regulates appetite. Its levels increase before a meal and decrease soon after ending a meal; this post-prandial suppression communicates satiety and food reward to the central nervous system (CNS). Although fasting ghrelin levels of obese individuals are lower than those of lean people, the absence of a physiological decrease after a meal explains their non-stop eating behavior [37,39]. In her paper, Spadafranca and her collaborators sustained the hypothesis of a link between ghrelin suppression and P. vulgaris extract administration [37]. In our study we cannot confirm this: Non-treated HFD mice had low ghrelin levels, but hormonal secretion appeared not to be influenced by the prolonged P. vulgaris extract treatment; ghrelin levels increased without reaching a statistical significance.

The results of the present study stressed another mechanism, the ability of $P$. vulgaris extract to negatively modulate enzymatic activity of pancreatic alpha-amylase, which in extract-treated HFD mice almost reached the levels of controls. Phaseolamin is, indeed, commonly recognized as a starch blocker, a compound which slows down the digestion of complex carbohydrates, and thus gastric emptying as well, due to the inhibition of $\alpha$-amylase enzymatic activity $[7,37,40]$.

A growing body of literature links prediabetes, obesity, and metabolic syndrome to the risk of diabetic peripheral neuropathy as well as cryptogenic sensory peripheral neuropathy [41]. On this basis, we focused on neurological impairments; in the HFD group we observed a decreased pain threshold, highlighting a condition that resembles mechanical allodynia, as well as altered motor coordination. Interestingly, these alterations were reverted only in the P. vulgaris extract treated-group. This point could be explained since phytotherapy is based on the combined action of a mixture of constituents able to offer a multiple approach to the multi-factorial nature of the metabolic syndrome. The bioactivity of crude drugs or vegetal extracts is a summation of antagonistic and/or synergistic effects on bioavailability, cellular transport processes, compound metabolism, and pharmacodynamic mechanisms, which could explain the positive effect of $P$. vulgaris extract also on pain threshold and motor alterations induced by HFD. On the contrary, metformin and atorvastatin, two drugs with a specific function and mechanism of action, are ineffective. No effects on thermal hyperalgesia or anxiety were recognized in HFD-fed animals. A similar annotation of metabolic syndrome fallouts on neurological behavior was published in a work by Takase and his colleagues, who observed that HFD evoked motorial disfunctions in mice, with no influences on anxiety [42].

A fat-enriched diet considerably affects the liver, the organ dedicated to lipid and lipoprotein metabolism, in addition to-and because of - the onset of glucose and insulin resistance. The increased circulating free fatty acids overload the liver with fat and cholesterol, causing hepatotoxicity, a state of dyslipidemia, excess fat deposing and cardiovascular diseases. In particular, the fatty diet and insulin resistance cause a switch from the physiological mitochondrial lipid oxidation to peroxidation of long chain fatty acids, which promotes lipotoxicity and extraordinary release of reactive oxygen species (ROS) [43]. 
The high fat diet caused a gain weight of liver and heart in the HFD mice, but it was significantly lowered by treatment with $P$. vulgaris extract. Also, the other steps of on-going metabolic syndrome were confirmed. Histological samples from the HFD group clearly showed hepatosteatosis, hepatic lipid peroxidation, and lipid accumulation in the cardiovascular system, such as the fatty streaks in the aorta. These disease-related negative consequences were reverted by $P$. vulgaris extract challenge.

As mentioned above, the excessive generation of ROS, when not counterbalanced by the antioxidant mechanisms, is a pathological condition which is dramatically augmented in metabolic syndrome, thus inducing the antioxidant defense system to change in relation to the new state. Protein carbonylation in the plasma, normally increased in a fat diet, was significantly reduced in P. vulgaris extract -treated mice, showing a protective role of the compound against this oxidative stress consequence. Conversely, it was not sufficient to protect the HFD heart, whose carbonylated proteins were not significantly diminished by the same treatment.

Aiming to study possible redox detoxifying mechanisms, we evaluated the expression levels of cardiac antioxidant enzymes. Catalase and GSH reductase were considerably more expressed in HFD hearts, probably obeying to a pathophysiological compensatory mechanism, to face the elevated cardiac ROS levels. $P$. vulgaris extract treatment raised the levels of all the antioxidant enzymes, except for NADH dehydrogenase which was slightly reduced.

\section{Conclusions}

The present standardized P. vulgaris extract counteracts molecular, biochemical, and behavioral alterations induced by HFD in a clinically-relevant model of metabolic syndrome. The wide range of activity, as well as the well assessed safety profile [40], makes P. vulgaris extract an intriguing candidate for a clinical use.

Supplementary Materials: The following are available online at http://www.mdpi.com/2072-6643/11/8/1778/s1, Materials and Methods, Table S1: Hematic metabolic parameters; Table S2: GTT and ITT AUC; Table S3: HOMA-IR; Table S4: Plantar test; Table S5: Elevated plus maze; Figure S1: Brain weight; and Figure S2: Kidney histological evaluation.

Author Contributions: All authors made a substantial contribution to the analysis and interpretation of the data and to the writing and revising of the manuscript. All authors reviewed the final version of the manuscript and gave permission to submit. L.D.C.M., A.C., A.P., and C.G. conceived the study, and revised and approved the manuscript. L.M., E.L., and E.T. performed the experiments and wrote the manuscript. C.D.C., C.A., and R.R. analyzed data, and revised and approved the manuscript.

Funding: This research was funded by the Italian Ministry of Instruction, University and Research (MIUR), and by the University of Florence.

Conflicts of Interest: The authors declare no conflict of interest.

\section{References}

1. Reaven, G.M. Resistance to insulin-stimulated glucose-uptake and hyperinsulinemia: Role in non-insulin-dependent diabetes, high blood-pressure, dyslipidemia and coronary heart disease. Diabetes Metab. 1991, 17, 78-86.

2. Grundy, S.M.; Cleeman, J.I.; Daniels, S.R.; Donato, K.A.; Eckel, R.H.; Franklin, B.A.; Gordon, D.J; Krauss, R.M.; Savage, P.J.; Smith, S.C.; et al. Diagnosis and management of the metabolic syndrome-An American Heart Association/National Heart, Lung, and Blood Institute Scientific Statement. Circulation 2005, 112, 2735-2752. [CrossRef] [PubMed]

3. Mariotti, F.; Hermier, D.; Sarrat, C.; Magne, J.; Fenart, E.; Evrard, J.; Tome, D.; Huneau, J.F. Rapeseed protein inhibits the initiation of insulin resistance by a high-saturated fat, high-sucrose diet in rats. Br. J. Nutr. 2008, 100, 984-991. [CrossRef] [PubMed]

4. Vijay-Kumar, M.; Aitken, J.D.; Carvalho, F.A.; Cullender, T.C.; Mwangi, S.; Srinivasan, S.; Sitaraman, S.V.; Knight, R.; Ley, R.E.; Gewirtz, A.T. Metabolic Syndrome and Altered Gut Microbiota in Mice Lacking Toll-Like Receptor 5. Science 2010, 328, 228-231. [CrossRef] [PubMed] 
5. Cicero, A.F.; Colletti, A. Role of phytochemicals in the management of metabolic syndrome. Phytomedicine 2016, 23, 1134-1144. [CrossRef] [PubMed]

6. Patti, A.M.; Al-Rasadi, K.; Giglio, R.V.; Nikolic, D.; Mannina, C.; Castellino, G.; Chianetta, R.; Banach, M.; Cicero, A.F.; Lippi, G.; et al. Natural approaches in metabolic syndrome management. Arch. Med. Sci. 2018, 14, 422-441. [CrossRef] [PubMed]

7. Obiro, W.C.; Zhang, T.; Jiang, B. The nutraceutical role of the Phaseolus vulgaris alpha-amylase inhibitor. Br. J. Nutr. 2008, 100, 1-12. [CrossRef]

8. Brain-Isasi, S.; Alvarez-Lueje, A.; Higgins, T.J.V. Heterologous expression of an alpha-amylase inhibitor from common bean (Phaseolus vulgaris) in Kluyveromyces lactis and Saccharomyces cerevisiae. Microb. Cell. Fact. 2017, 16, 110. [CrossRef]

9. Bowman, D.E. Amylase inhibitor of navy beans. Science 1945, 102, 358-359. [CrossRef]

10. Marshall, J.J.; Lauda, C.M. Purification and properties of phaseolamin, an inhibitor of alpha-amylase, from the kidney bean, Phaseolus vulgaris. J. Biol. Chem. 1975, 250, 8030-8037.

11. Oliveira, R.J.S.; De Oliveira, V.N.; Deconte, S.R.; Calabria, L.K.; Moraes, A.d.S.; Espindola, F.S. Phaseolamin treatment prevents oxidative stress and collagen deposition in the hearts of streptozotocin-induced diabetic rats. Diab. Vasc. Dis. Res. 2014, 11, 110-117. [CrossRef] [PubMed]

12. McGrath, J.C.; Lilley, E. Implementing guidelines on reporting research using animals (ARRIVE etc.): New requirements for publication in BJP. Br. J. Pharmacol. 2015, 172, 3189-3193. [CrossRef] [PubMed]

13. Mali, V.R.; Ning, R.; Chen, J.; Yang, X.P.; Xu, J.; Palaniyandi, S.S. Impairment of aldehyde dehydrogenase-2 by 4-hydroxy-2-nonenal adduct formation and cardiomyocyte hypertrophy in mice fed a high-fat diet and injected with low-dose streptozotocin. Exp. Biol. Med. 2014, 239, 610-618. [CrossRef] [PubMed]

14. Reed, M.J.; Meszaros, K.; Entes, L.J.; Claypool, M.D.; Pinkett, J.G.; Gadbois, T.M.; Reaven, G.M. A new model of type 2 diabetes: The fat-fed streptozotocin-treated rat. Metabolism 2000, 49, 1390-1394. [CrossRef] [PubMed]

15. Srinivasan, K.; Viswanad, B.; Asrat, L.; Kaul, C.L.; Ramarao, P. Combination of high-fat diet-fed and low-dose streptozotocin-treated rat: A model for type 2 diabetes and pharmacological screening. Pharmacol. Res. 2005, 52, 313-320. [CrossRef] [PubMed]

16. Watanabe, Y.; Nakamura, T.; Ishikawa, S.; Fujisaka, S.; Usui, I.; Tsuneyama, K.; Ichihara, Y.; Wada, T.; Hirata, Y.; Suganami, T.; et al. The radioprotective 105/MD-1 complex contributes to diet-induced obesity and adipose tissue inflammation. Diabetes 2012, 61, 1199-1209. [CrossRef]

17. Fantini, N.; Cabras, C.; Lobina, C.; Colombo, G.; Gessa, G.L.; Riva, A.; Donzelli, F.; Morazzoni, P.; Bombardelli, E.; Carai, M.A.M. Reducing effect of a Phaseolus vulgaris dry extract on food intake, body weight, and glycemia in rats. J. Agric. Food. Chem. 2009, 57, 9316-9323. [CrossRef]

18. Loi, B.; Fantini, N.; Colombo, G.; Gessa, G.L.; Riva, A.; Bombardelli, E.; Morazzoni, P.; Carai, M.A.M. Reducing effect of an extract of Phaseolus vulgaris on food intake in mice-focus on highly palatable foods. Fitoterapia 2013, 85, 14-19. [CrossRef]

19. Gao, X.; Nan, Y.; Zhao, Y.; Yaun, Y.; Ren, B.; Sun, C.; Cao, K.; Yu, M.; Feng, X.; Ye, J. Atorvastatin reduces lipid accumulation in the liver by activating protein kinase A-mediated phosphorylation of perilipin 5. Biochim. Biophys. Acta. Mol. Cell. Biol. Lipids 2017, 1862, 1512-1519. [CrossRef]

20. Wang, J.H.; Bose, S.; Shin, N.R.; Chin, Y.W.; Choi, Y.H.; Kim, H. Pharmaceutical impact of Houttuynia Cordata and metformin combination on high-fat-diet-induced metabolic disorders: Link to intestinal microbiota and metabolic endotoxemia. Front. Endocrinol. (Lousanne) 2018, 9, 620. [CrossRef]

21. Vaught, J.; Pelley, K.; Costa, L.G.; Sether, P.; Enna, S.J. A comparison of the antinociceptive responses to GABA-receptor agonists THIP and baclofen. Neuropharmacology 1985, 24, 211-216. [CrossRef]

22. Baptista-de-Souza, D.; Di Cesare Mannelli, L.; Zanardelli, M.; Micheli, L.; Nunes-de-Souza, R.L.; Canto-de-Souza, A.; Ghelardini, C. Serotonergic modulation in neuropathy induced by oxaliplatin: Effect on the 5HT2C receptor. Eur. J. Pharmacol. 2014, 735, 141-149. [CrossRef]

23. Hargreaves, K.M.; Dubner, R.; Brown, F.; Flores, C.; Joris, J. A New and Sensitive Method for Measuring Thermal Nociception in Cutaneous Hyperalgesia. Pain 1988, 32, 77-88. [CrossRef]

24. Komada, M.; Takao, K.; Miyakawa, T. Elevated plus maze for mice. J. Vis. Exp. 2008. [CrossRef]

25. Shoji, H.; Takao, K.; Hattori, S.; Miyakawa, T. Age-related changes in behaviour in C57BL/6J mice from young adulthood to middle age. Mol. Brain 2016, 9, 11. [CrossRef] 
26. Zhang, Y.; Si, Y.; Yao, S.; Yang, N.; Song, G.; Sang, H.; Zu, D.; Xu, X.; Wang, J.; Qin, S. Celastrus orbiculatus Thunb. decreases athero-susceptibility in lipoproteins and the aorta of guinea pigs fed high fat diet. Lipids 2013, 48, 619-631. [CrossRef]

27. Cinci, L.; Corti, F.; Di Cesare Mannelli, L.; Micheli, L.; Zanardelli, M.; Ghelardini, C. Oxidative, metabolic, and apoptotic responses of Schwann cells to high glucose levels. J. Biochem. Mol. Toxicol. 2015, 29, 274-279. [CrossRef]

28. McGuinness, P.O.; Ayala, J.E.; Laughlin, M.R.; Wasserman, D.H. NIH experiment in centralized mouse phenotyping: The Vanderbilt experience and recommendations for evaluating glucose homeostasis in the mouse. Am. J. Physiol. Endocrinol. Metab. 2009, 297, E849-E855. [CrossRef]

29. Fellmann, L.; Nascimento, A.R.; Tibirica, E.; Bousquet, P. Murine models for pharmacological studies of the metabolic syndrome. Pharmacol. Ther. 2013, 137, 331-340. [CrossRef]

30. Carai, M.A.; Fantini, N.; Loi, B.; Colombo, G.; Gessa, G.L.; Riva, A.; Bombardelli, E.; Morazzoni, P. Multiple cycles of repeated treatments with a Phaseolus vulgaris dry extract reduce food intake and body weight in obese rats. Br. J. Nutr. 2011, 106, 762-768. [CrossRef]

31. Lorrai, I.; Piga, V.; Carai, M.A.; Riva, A.; Morazzoni, P.; Gessa, G.L.; Colombo, G.; Maccioni, P. A Phaseolus vulgaris Extract Reduces Cue-Induced Reinstatement of Chocolate Seeking in Rats. Front. Pharmacol. 2016, 7, 109. [CrossRef]

32. Reverri, E.J.; Randolph, J.M.; Kappagoda, C.T.; Park, E.; Edirisinghe, I.; Burton-Freeman, B.M. Assessing beans as a source of intrinsic fiber on satiety in men and women with metabolic syndrome. Appetite 2017, 118, 75-81. [CrossRef]

33. Tormo, M.A.; Gil-Exojo, I.; De Tejada, A.R.; Campillo, J.E. Hypoglycaemic and anorexigenic activities of an alpha-amylase inhibitor from white kidney beans (Phaseolus vulgaris) in Wistar rats. Br. J. Nutr. 2004, 92, 785-790. [CrossRef]

34. Nuñez-Aragón, P.N.; Segura-Campos, M.; Negrete-León, E.; Acevedo-Fernández, J.J.; Betancur-Ancona, D.; Chel-Guerrero, L.; Castañeda-Corral, G. Protein hydrolysates and ultrafiltered $<1 \mathrm{KDa}$ fractions from Phaseolus lunatus, Phaseolus vulgaris and Mucuna pruriens exhibit antihyperglycemic activity, intestinal glucose absorption and $\alpha$-glucosidase inhibition with no acute toxicity in rodents. J. Sci Food Agric. 2019, 99, 587-595.

35. Tormo, M.A.; Gil-Exojo, I.; de Tejada, A.R.; Campillo, J.E. White bean amylase inhibitor administered orally reduces glycaemia in type 2 diabetic rats. Br. J. Nutr. 2006, 96, 539-544.

36. Barrett, M.L.; Udani, J.K. A proprietary alpha-amylase inhibitor from white bean (Phaseolus vulgaris): A review of clinical studies on weight loss and glycemic control. Nutr. J. 2011, 10, 24. [CrossRef]

37. Spadafranca, A.; Rinelli, S.; Riva, A.; Morazzoni, P.; Magni, P.; Bertoli, S.; Battezzati, A. Phaseolus vulgaris extract affects glycometabolic and appetite control in healthy human subjects. Br. J. Nutr. 2013, 109, 1789-1795. [CrossRef]

38. Dali-Youcef, N.; Mecili, M.; Ricci, R.; Andres, E. Metabolic inflammation: Connecting obesity and insulin resistance. Ann. Med. 2013, 45, 242-253. [CrossRef]

39. Guarino, D.; Nannipieri, M.; Iervasi, G.; Taddei, S.; Bruno, R.M. The role of the autonomic nervous system in the pathophysiology of obesity. Front. Physiol. 2017, 8, 665. [CrossRef]

40. Chokshi, D. Subchronic oral toxicity of a standardized white kidney bean (Phaseolus vulgaris) extract in rats. Food Chem. Toxicol. 2007, 45, 32-40. [CrossRef]

41. Stino, A.M.; Smith, A.G. Peripheral neuropathy in prediabetes and the metabolic syndrome. J. Diabetes Investig. 2017, 8, 646-655. [CrossRef]

42. Takase, K.; Tsuneoka, Y.; Oda, S.; Kuroda, M.; Funato, H. High-fat diet feeding alters olfactory-, social-, and reward-related behaviors of mice independent of obesity. Obesity 2016, 24, 886-894. [CrossRef]

43. Bechmann, L.P.; Hannivoort, R.A.; Gerken, G.; Hotamisligil, G.S.; Trauner, M.; Canbay, A. The interaction of hepatic lipid and glucose metabolism in liver diseases. J. Hepatol. 2012, 56, 952-964. [CrossRef]

(C) 2019 by the authors. Licensee MDPI, Basel, Switzerland. This article is an open access article distributed under the terms and conditions of the Creative Commons Attribution (CC BY) license (http://creativecommons.org/licenses/by/4.0/). 